\title{
The Perception of English Modals among Arab Language Learners
}

\author{
Mahmoud Al-Qudah \\ Princess Sumayya University for Technology (PSUT), Amman, 11941 Jordan \\ Ayman Yasin (Corresponding author) \\ Princess Sumayya University for Technology (PSUT), Amman, 11941 Jordan \\ E-mail: a.yasin@psut.edu.jo
}

Received: 19-12-2015

Published: 01-05-2016
Accepted: 07-03-2016

doi:10.7575/aiac.ijalel.v.5n.3p.282
Advance Access Published: March 2016

URL: http://dx.doi.org/10.7575/aiac.ijalel.v.5n.3p.282

\begin{abstract}
This paper aims at investigating the acquisition of English modality among Arab learners of English as a foreign language. Specifically, the study limits itself to the perception of modal verbs as a means of expressing modality. The productive use of modal verbs were analyzed by examining written texts made by 26 fourth-year students majoring in Applied English at the University of Jordan. Moreover, the meaning and function of modal verbs were investigated by asking the subjects to explicitly determine them in given sentences. The subjects were also asked to translate these sentences into their native language in an attempt to investigate the effect of the native language on the perception of modality. The study concludes that there is a gap in the use of English modal verbs as a way of expressing modality. It was found that the differences between Arabic and English modality seems to play an integral role in the misperception of English modality among Arab learners. Other factors, like teaching methods, seem to widen the gap.
\end{abstract}

Keywords: modality, modal verbs, Arabic, translation

\section{Introduction}

The broad term of modality may be regarded as a vague and a controversial one. Searching through the meaning of modality, it is noted that linguists adopt different approaches when clarifying modality. Being identified as a semantic term, Palmer (1979:16) defines modality as "the grammaticalization of speaker's (subjective) attitudes and opinions". Hence, Palmer analyzed modality by the use of 'modals' which causes the circularity of the definition. However, Brewer (1987) criticized Palmer's modality of being realized apart from referring to semantic considerations. For Brewer, 'modals' can be formed according to formal criteria and without any need to refer to semantic considerations.

In the semantics analysis, modality operates at the sentence level. It also refers to the various devices used by the speakers to express the varying degrees of commitment to a proposition. In this view, moods are analyzed as means of expressing modality that are related to verb forms or inflections (Saeed, 1997).

However, from a grammatical perspective, modality has been discussed differently. For Halliday (2014:172), the meaning of modality is narrowed down to the "the speaker's judgment, or request of the judgment of the listener, on the status of what is being said". These judgments fall in between the polarity's poles of yes or no, i.e. the intermediate degrees of modality lie between the negative and the positive poles of polarity. In other words, the modality system illustrates the uncertainty or the possibilities that occurred between yes or no. Halliday (2014) classified modality as being an element of mood. In this regard, mood is the umbrella term that is composed of modality and polarity. Notably, Halliday's moods are analyzed at the clause level.

Reviewing the related literature, the lack of well-established studies on the topic of the acquisition of English modality among Arab learners is noticed. However, the few studies conducted on this topic indicate that there is low performance of learners of English in the perception of modality. Thus, this study is an attempt to clarify the acquisition of English modality among Arab learners of English as a foreign language.

\section{Literature Review}

Modality has been defined in different ways due to the different perspectives from which modality has been examined. Semantically, modality is viewed as the umbrella term under which moods and modes are recognized (Palmer, 1979; Saeed, 1997). On the other hand, it can be grammatically analyzed as a mood's element (Halliday, 2014). Perhaps, the nature of modality as a system of showing the 'speaker's attitude' towards a proposition causes this overlap. Besga (1995) reached the same conclusion and confirmed that the vagueness of modality as a topic of study resulted from two main reasons. The first is not having a clear definition of modality, and the other is related to the different types of modality. 
The broadness of modality and the 'intermediacy' nature of it seem to affect the researchers' choice of studying modality. This can be noticed among the reviewed literature on the topic of modality, since most of the studies tend to be narrowed down to examining the role of modal verbs in expressing modality (Badran, 2001). For instance, in his study, Brewer (1987) investigates the meaning of English modality and fractivity by limiting his work to modal auxiliaries. Similarly, Badran (2001) studies English modality in political texts making use of modal verbs. In addition, modal auxiliaries are found to play a crucial role in expressing modality in the statement of objectives for academic papers (Olaniyan, 2015)

However, the problem seems to be more complicated when it comes to Arabic modality. The main reason for such a case may be due to the fact that the term modality is not found in the Arabic linguistic. Yet, the idea of modality and moods as a means to express the speaker's attitudes and judgments is clearly discussed. In Arabic, both concepts are covered under the study of the meanings of the types of sentences and the devices used for that purpose. Thus, in an attempt to overcome this, it seems that the Arabic studies of modality have their own indirect way of investigating it. This seems to be realized either by the means of examining modality in a specialized context or through performing contrastive studies. In a biomedical discourse, Wided (2010) investigates the deontic modality in English, French and Arabic. He finds remarkable differences among the three languages since each language expresses deontic modality by the use of certain fixed expressions. Mukhaini (2008) traces English and Arabic modality in legal context. He confirms that despite the differences in expressing modality between the two languages, both languages provide similar syntacticsemantic realization of modality. In a study about Arabic and English modality in translation, Al Qinai (2008) studies the use of modal verbs in translated texts. He confirms that modality can not only be expressed through the means of verbs, but it can also be guessed from the context.

In an attempt to have a fixed background in the topic of modality, Moshref (2012) creates an Arabic corpus for this purpose. Yet, she limits her study to modal verbs. Regarding Arabic modality and corpus building, Al-Sabbagh, Disner and Girjul (2013) try to set rules of Arabic modality in order to ease the task of annotating them. However, the nature of modality and the fact that there is no fixed rules of forming it are the main obstacles for their research.

Concerning the acquisition of modality among Arab learners of English, Sabri (2011) investigates the perception of English modality among Iraqi learners of English as a foreign language. He finds that the examined learners mastered the use of 'would' when expressing offer, whereas they failed to express deduction using 'must'. Moreover, Sabri (2011) asserts that the past tense of the modal verb 'shall' causes a problem to Iraqi learners of English, as they used 'should' instead of 'would'. Similarly, Saeed (2009) pinpoints that the Arab learners of English do not master English modals at the levels of recognition and production.

Problems in the acquisition of modal verbs of obligation by Macedonian Learners of English were noticed by Mitkovska et al. (2014) who elaborate that the influence of the mother tongue plays an essential role in the acquisition of modal verbs.

When it comes to Halliday's mood, it is noteworthy pointing that he distinguishes between "mood" and "mode". The former operates as a system of the clause, whereas the latter refers to verbal contrasts from the clausal system of mood. Thus, mode is the interpersonal system of the verb such as subjunctive, indicative, and optative mode.

At the 'traditional modal logic', Lyons, (1977) classifies modality into epistemic and deontic. While epistemic modality indicates the possibility and the probability of the occurrence of an event, the deontic modality shows obligation and necessity of it. Along the same lines, Palmer (1989) classifies two main classes of modality: propositional and event modality. The propositional modality's main concern is the speaker's attitude to the truth value of the proposition and it is subdivided into epistemic and evidential modality. The labels of these subcategories of modality indicate their nature, i.e. the epistemic elaborates the speaker's judgment about the factuality of the proposition, whereas the evidential sheds light on the evidence that the speakers have for their judgments. Similarly, the event modality refers to the potential events that are not actualized. The event modality too is divided into deontic modality and dynamic modality. Here, the deontic modality is limited to the obligations and permissions given by the speakers, whereas the dynamic modality refers to the abilities, willingness and wishes (ibid).

Another classification of modality can be highlighted according to the events themselves: realis and irrealis. Realis modality is used to describe events that are in the real world, whereas irrealis is used for events in the future, past or in the imaginary world (Saeed, 1997).

\subsection{The Study Questions}

The acquisition of modality as a system of expressing the speaker's attitude toward a proposition may be regarded as a complicated process. This may be due to the 'intermediacy' nature of modality and the different ways of expressing modality. Thus, the acquisition of modality seems to be a good indicator of being at a higher level of the foreign language.

This study tries to find answers to the following questions:

1. a. Do Arab learners of English as a foreign language master the use of modal verbs as a way of expressing modality?

b. What are the factors that affect the Arab learners' acquisition of English modality? 
In an attempt to investigate the similarities and differences between the modality systems of English and Arabic, the modality systems of each language would be discussed below.

\subsection{English Modality}

English modality can be expressed lexically and grammatically. The most common way that has been highlighted by different researcher is the use of modal verbs. Some researchers as Perkins (1980) sheds light on the centrality of modal auxiliaries within the system of modality. English modal verbs indicate various degrees of possibility, probability, necessity or certainty, and can be used in the present and past tenses to express these functions. However, not all of the meanings of modal verbs express modality, since some modal verbs are used to express future actions.

Other devices can be used to express modality, Perkins (1980) explains that they can be in the form of:

2. a. Quasi-auxiliary modal expressions such as have got to, had better.

b. Modal expressions incorporating adjectives and participles like be going to, be willing to, be evident that.

c. Modal adverbs, such as allegedly, clearly, perhaps, surely, etc.

d. Modal nominal like belief, obligation, proposal, warning, etc.

e. Modal lexical verbs as allow, conclude, hope, promise, etc.

f. Modal 'devices' are used to express irrealis modality like:

i. Tense as in I wish I were.

ii. If-clauses as in: If I were rich, I would buy Ferrari.

Saeed (1997) too refers that modality can be realized by means of using certain syntactic structures. One way of doing so is embedding the sentence under a higher clause that have a modal expression as in it is certain that ---- and it is probable that----. Another way is formed by having the modal verb in the higher clause as in: $I$ know that $S$ and $I$ believe that $S$.

This study will be concerned with the English modality expressed by modal verbs. The perception of the learners toward the various degrees of possibility, probability, necessity or certainty expressed by modal verbs would be examined. Here, the differences between the use of modal verbs in the present and the past tense would be highlighted.

\subsection{Arabic Modality}

Flicking through the Arabic semantic books and papers, it is founded that the terms "modality" and "mood" are not used among the traditional Arab linguists, who lived in the $8^{\text {th }}-10^{\text {th }}$ century AD. Yet, the notions of modality and mood as a means to express the speaker's attitude and judgments are clearly discussed.

In Arabic, both concepts are covered under the study of the meanings of sentence types and the devices used for forming them. The two main types of Arabic sentences are the informative sentences, Pal-dzumal Pal-xabarijja and the compositional sentences ?al-dzumal ?al-Pinfa:?ijja. The informative sentence refers to the type of sentences that is used to describe facts and events in the real situations (Amin, 1979). Here, the speaker forms such sentences in order to inform something. The truth conditions of such type have to be examined by referring to the real situation:
3. Thahab-a
Salijj-un Pila
1-madrasa-t-i
go:PAST-IND Ali-NOM to
the-school-F-GEN

'Ali went to school'

The sentence in (3) suggests that informative sentences match the indicative mood. On the other hand, the imperative and the subjunctive moods are realized under different types of compositional sentences which are that type of sentences formed by the speakers to refer to events and situations that are not found in the real world. The truth conditions of such sentences cannot be investigated and thus the speaker cannot be judged as a truthful or a liar. This is what distinguishes the compositional sentences from the informative ones (Amin, 1979:55).

There are various types of compositional sentences, but the discussion will be narrowed down to the types that indicate modality and mood properties. The first type of compositional sentences refers to the highest degree of the speaker's volition to perform an action; it is the vow construction ' $u$ slu:b al-qasam'.
4. wa-llah-i
la-?adrus-a-nn
I swear-Allab-GEN
EMPH-study-SUBJ-EMPH

'I swear (by Allah) I am going to study'

Here, the highest degree of the speaker's volition to study appears from the use of the swear particle $w a$-, and the use of the emphatic proclitic la- and enclitic - $n n$ that are attached to the verb.

The wishing construction in Arabic 'uslu:b ar-radza:?' expresses the speaker's hopes and wishes of something to happen. It is also used as a comment to show sympathy for something that happened in the past. An example of the first use of this type is: 
5. Sasa llah-u Pan ja-nsSur-a-na:

may Allah-NOM that IMPF-give victory-SUBJ-1PL:ACC

'We wish that Allah will help us in our way to victory'

Certain verbs, such as Sasa are used to express the possibility of the event to occur. It is noteworthy here that sentences including such verbs have to be formed according to certain syntactical structures. Therefore, it can be inferred that modality in Arabic can be realized lexically and structurally simultaneously.

On the other hand, there are certain particles that are also used to refer to wishes and hopes or to make comments for past events. These particles are lajta 'wish' and laSalla 'hope'. However, the context plays an integral role in determining the meaning of these particles as shown in the following examples:

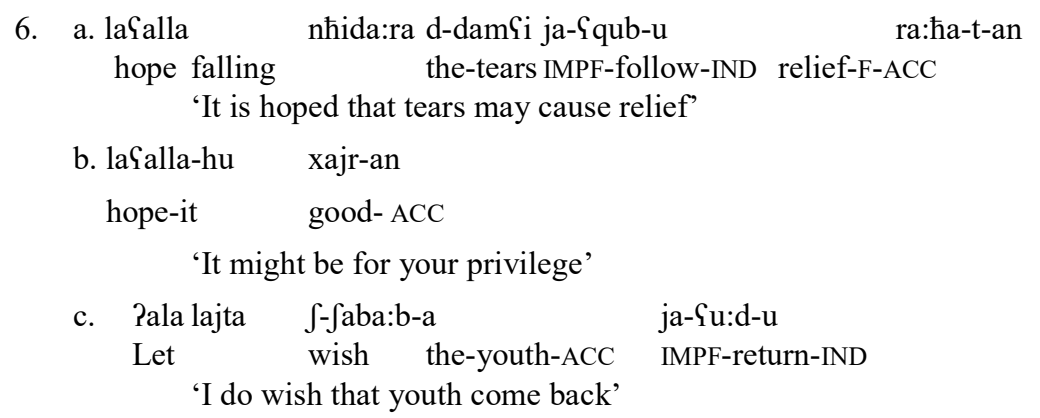

It is noted that a realis modality is indicated in (6a), whereas an irrealis modality is found in (6b\&c).

There are other ways of pointing to irrealis modality like using interrogative sentences to indicate that something impossible may occur. Irrealis modality may also be captured through the use of certain expressions like:

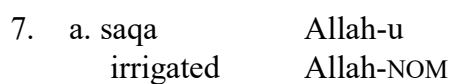

'What a pity (for the past)'

b. rahima Allah-u

mercy Allah-NOM

'May Allah have his mercy on'

c. Sala Allah-i

on Allah-GEN

'Leave it to Allah'

d. li-llah-i darr-u-k

for-Allah-GEN milk-NOM-your

'May Allah reward you'

Once more, the context plays a crucial role in indicating the meaning and the polarity of such type of modality, i.e. whether the irrealis modality refers to positive or negative proposition. For example when the expression saqa Allah 'What a pity' is found in a sentence that describes past events or situations, it indicates a positive attitude as in:
8. a. saqa
Allah-u Rajjam-a S-Siba:
irrigated Allah-NOM days-ACC
the-youth

'I long for the days of youth'

On the other hand, this expression indicates negative attitude when it is used to refer to the future:
9. a. saqa
Allah-u fura:q-a-k
irrigated
Allah-NOM
leaving-ACC-you

'I wish to get rid of you'

Studying these expressions carefully, it can be inferred how the Arabic environment affects the semantic choice of modality. Knowing that our ancestor Arabs made their living by farming and raising cattle seems to be the reason beyond the modality of such expressions. Moreover, it can be noticed that the Arabs alluded everything in their lives to Allah and his willing as evident in these expressions. This conclusion matches Brewer's argument for the role of the environment in the selection of modality (Brewer, 1987). 
On the other hand, Arabic realis modality can be formed by the use of certain verbs that refer to possibility, probability, or certainty. It has to be highlighted here that the verbs used here indicate various degrees of possibility, probability, and certainty:
10. a. jumkinu 'may'
b. justahsanu 'it is better'
c. jufaDDalu 'it is preferred'
d. juhabbathu 'I would rather'
e. juTHannu 'It is dubted'

In addition, such modality can be observed through the use of certain syntactic structures and certain modal expressions:
11. a. mina 1-mumkini 'It is possible'
b. mina 1-muhtamili 'It is probable'
c. mina 1-mustahi:li 'It is impossible'
d. mina 1-muftaraDi 'It is supposed that'

To sum up, it can be concluded that Arabic modality is expressed in different ways:

12. a. The use of certain modal expression within fixed syntactic structure, like the wishing construction.

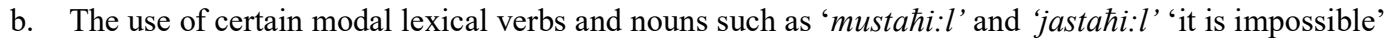

c. The use of certain fixed expressions in certain contexts that determine their polarity.

$2.5 \mathrm{Mood}$

Apart from Halliday's definition, mood can be defined as the property of verbs that indicates the speaker's attitude toward the factuality or possibility of an expressed action or condition (Huddlestone, 1984). It is achieved through a set of verb forms or inflections (Saeed, 1997). In this regard, the 'mode' of Halliday's (2014) interpersonal system of verb can be realized through the use of some modal verbs.

There are several types of mood which vary according to the factual attitudes expressed by the speakers. The major three kinds of mood in Arabic are the indicative mood, the imperative mood, and the subjunctive mood (Huddlestone, 1984; Saeed, 1997). The indicative mood is used to describe factual or real situations like making factual statements, asking questions, or expressing opinions as if they were facts:
13. a. Ahmadu
mari:D-un
Ahmad-NOM sick-NOM

'Ahmad is sick'

The imperative mood expresses commands, orders, or request. .It reveals the speaker's desires for the action expressed in the sentence to take place:
14. tana:wal TaSa:ma-k
have food-your
'Have your food'

The subjunctive mood, however, is used for conditional or imaginary situations. It does not refer to factual situation; rather, it expresses wishes, doubts, or any situation contrary to facts:
15. Pa-amanna law kun-tu
I-wish
if was-I
muha:sib-an
'I wish I were an accountant'
accountant-ACC

Huddlestone (1984) distinguishes other minor moods like English tag declarative, tag imperative, pseudo-imperative, and exclamative as in:

16. a. You've been stealing again, haven't you?

b. Go out, will you.

c. Move and I'll shoot!

d. What a nice house!

In general, Jumingac and Othmand (2015) distinguish five different types of moods in Arabic, which are the indicative, subjunctive, jussive, imperative and emphatic moods. 


\section{Methodology}

The perception of English modal verbs as a mean of expressing modality were analyzed for 26 fourth year students majoring in Applied English at the University of Jordan. Several steps were followed to assess the perception of English modal verbs.

The first of which was analyzing the productive use of modal verbs that occurred in written texts made by the subjects. The texts were about the students' responsibilities in the field of a training course. Thus, a good amount of imperative and subjunctive mood would be used, i.e. verbs that would indicate obligation, command, necessity, etc.

The second step was measuring the perception of the meanings and functions of modal verbs. This was carried out by means of a questionnaire (see the appendix). The questionnaire consisted of two parts. The first part is composed of two pairs of sentences; each pair has a different type of modality which was expressed by the use of the past tense of modal verb such as shall vs. should, and can vs. could. In this part, the students were asked to determine whether the sentences share the same meaning or not. In case they indicated that the sentences did not share the same meaning, they had to specify why and how they differed from each other.

To double check the subjects' knowledge of modality expressed by modal verbs, the subjects were also asked to translate the sentences into their native language. This was done in order to investigate the effect of the native language on the perception of modality, if there was any.

Finally, the written texts and the questionnaire were collected, tabulated and analyzed.

\section{Findings and Discussions}

Regarding the written task, it was found that $60 \%$ of the students did not use any modal to express obligation or necessity; instead they preferred to use the infinitive preceded by a phrase like 'my responsibilities':

17. The main responsibility is to translate medical texts from English to Arabic.

However, $15 \%$ of the students expressed the same task by using lexical verbs like 'suppose':

18. I am supposed to collect the students' notebook.

The other $25 \%$ of the subject referred to obligation by making use of modal verbs. However, it is noted that most of them used only the modal verb 'should' for the task:

19. I should answer the phone calls.

The use of the modal verb 'should' to refer to obligation and ruling out any other variation of modal verbs may indicate the low performance of the students regarding the modal verbs. Here, it can be inferred that the flexibility of the modal 'should' is the reason beyond its usage in the students' writing since should refers to advice and obligation. Sabri (2011) maintains that when it comes to obligation, should is commonly used by language learners more than must which only expresses necessity or strong obligation.

It is evident, then, that students are not fully aware of the different uses of modal verbs, i.e. they opted for using other structures and when they used modal verbs, they struck to using only one modal. Only a third of the subjects made use of should.

For the second procedure of assessing the students' perception of the meaning and the function of the modal verbs in sentences, it was found that $53 \%$ of the students indicated that the two pairs of sentences share the same meaning. In addition, $33 \%$ of the students asserted that the first couple of sentences $(20 \mathrm{a} \& \mathrm{~b})$ have the same meaning, whereas the second couple $(21 \mathrm{a} \& \mathrm{~b})$ do not. $12 \%$ of them claimed that the two couples of sentences do not convey the same meaning. However, they did not know why and how the first couple differ in meaning.

20. a. I shall eat my breakfast.

b. I should eat my breakfast

21. a. Can you help me do my math assignments?

b. Could you help me do my math assignments?

From the overall percentages, it seems that students could not differentiate between the meaning and the use of the modal verbs in the present and past tense. This is clearest in the case of shall and should. It seems that they do not know that shall in the first sentence lays an obligation to be done in the future, whereas should expresses an irrealis modality about an action.

Different reasons may cause such a confusion. One of these reasons may be the effect of L1 Strategy and L2 Strategy. This is because modality as a system is found in both of Arabic and English, yet the devices of expressing it is different in the two languages. For example, the difference of the use of the past tense and the present tense in Arabic to express 
the speaker's attitude is expressed by the particle qad before verbs to either indicate emphasis when it comes before a past tense verb, or possibility when preceding present tense:

$\begin{array}{ll}\text { 22. a. qad } & \text { daras-tu d-dars-a } \\ \text { Indeed } & \text { study:PST-1S the-lesson-ACC }\end{array}$

'I have indeed studied the lesson'

$\begin{array}{lll}\text { b. qad } & \text { Pa-drus-u } & \text { d-dars-a } \\ \text { perhaps } & \text { IMPF:1SM-study:IND } & \text { the-lesson-ACC }\end{array}$

'I may study the lesson'

Here, it is noteworthy highlighting that in the previous Arabic examples, modality was expressed through the use of lexical verbs and not modal verbs as it can happen in some cases in English. This may indicate that unless the students were taught or being exposed to such usage of modal verbs, they cannot master them.

With regard to the second couple of sentences, $45 \%$ realized that there is a difference between can and could in interrogative sentences. Studying the reason for this, it is likely that most of the students refer to the formality of the use of could, i.e. they consider that could is more polite than can. Notably, the students' curriculum covers such cases of modals. However, only few modal verbs are covered and not all functions are studied. The most crucial point to stress here is that the teachers focus on the grammatical aspects of modal verbs. In other words, they teach the students the environment in which these modals occur and the students depend solely on the literal translation of the modals. However, the students are not given the chance to grasp the functions of the different modal verbs, neither are they taught in a communicative way that focuses on the use and function of every structure in the language rather than on the grammatical and translational aspects of it. In brief, the method of teaching English in general and modal auxiliaries in particular is the main reason behind the dissatisfactory achievement of the students even when they are majoring in English.

In the translation part of the given sentences, it was found that most of the subjects gave one translation for each couple of sentences. Thus, a misunderstanding of the use of some modal verbs in certain context must have occurred. This is especially the case for the $45 \%$ of the students who indicated that there wasn't any difference in the use and function of the second couple.

In sum, it seems that the use of English modal verbs to express modality is not fully perceived by the Arab learners of English.

\section{Conclusion and Recommendation}

This study focused on the proper use of some modal verbs by Arab learners of English. It was found that there was a gap in the use of English modal verbs as a way of expressing modality. The differences between Arabic and English modality seem to play a crucial role for the misperception of English modality among Arab learners. Other factors such as the teaching method seems to widen the gap since it focuses on grammar and translation rather than on using the communicative approach. Thus, the study recommends taking action toward the acquisition of modality. Arab language learners of English need to be exposed to the different meanings and uses of modal verbs in a communicative environment.

\section{References}

Al-Sabbagh, R., Diesner, J. and Girju, R. (2013). 'Using the semantic-syntactic interface for reliable Arabic modality annotation'. International Joint Conference on Natural Language Processing, pp.410-418.

Amin, B. (1979). The Arabic Eloquence in its New Form. Lebanon: Dar El-Ilm Lilmalayin.

Al Qinai, Jamal (2008). 'Pragmatic Interpretation in Translated texts'. Vigo International Journal of Applied Linguistics. 5: 9-36.

Badran, D. (2001). 'Modality and ideology in translated political texts'. Nottingham Linguistic Circular, 16: 41-61.

Besga, C (1995). 'Modals and Modality in English'. Miscelánea: A journal of English and American studies, 16: 165188.

Brewer, N.M. (1987). Modality and factivity: one perspective on the meaning of English modal auxiliary. PhD dissertation, University of Leeds.

Halliday, M.A.K. (2014). Introduction to Functional Grammar. London: Routledge.

Huddlestone, R. (1984). Introduction to the Grammar of English. Cambridge: Cambridge University Press.

Jumingac, M.F. amd Othmand, M.S. (2015). 'Critical review about the differences of the linguistic mood between Arabic and English languages'. Journal of Advances in Linguistics. 5(3): 661-666.

Lyons, J (1977). Semantics. Cambridge: Cambridge University Press. 
Mitkovska, Liljana and Buzarovska, Eleni and Kusevska, Marija (2014) 'Corpus evidence for the acquisition of modal verbs of obligation by Macedonian Learners of English'. Continual professional development - opportunities and challenges, 1(1): 55-63.

Moshref, O.A. (2012). Corpus Study of Tense, Aspect, and Modality in Diglossic Speech in Cairine Arabic. PhD. Dissertation, University of Illinois.

Mukhaini, Yasser (2008). Modality in Legal Texts: an Analytic study in Translation between English and Arabic. PhD Dissertation, Universiti Sains Malaysia.

Olaniyan, K. (2015). 'Modality in statement of objectives in art-based research article abstracts'. British Journal of English Linguistics, 3(1): 42-51.

Palmer, F R. (1979). Modality and the English Modals. London: Longman.

Perkins, Michael. (1980). The Expression of Modality in English. Doctoral dissertation, Council for National Academic Awards.

Saeed, J.I. (1997). Semantics. Oxford: Blackwell Publishers Ltd.

Saeed, A. T. (2009). 'Arab learners' acquisition of modals'. Research in Language, 7: 75-98.

Sabri, N. (2011). 'The Iraqi learners' acquisition order of epistemic and deontic modal verbs'. The Journal of Kuliat Al ma'moo Al Jameah. 18: 1-26.

Wided, B. (2010). Modality in English, French and Arabic Biomedical Discourse: A Contrastive Study of Drug Information Leaflets .MA. Dissertation, Mentouri University.

\section{Appendix:}

Questionnaire:

Part1: Indicate whether each couple of sentences shares the same meaning or not. In case of 'not' elaborate why and how they differ?

a. I shall eat my breakfast.

b. I should eat my breakfast

Answer:

c. Can you help me in do my math assignments?

d. Could you help me in do my math assignments?

Answer:

Part 2: Translate the previous sentences into Arabic. 